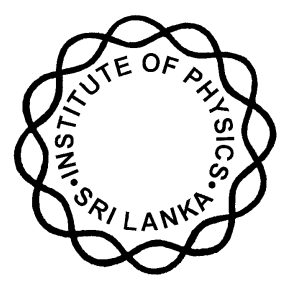

INSTITUTE OF PHYSICS - SRI LANKA

Research Article

\title{
Mesoscale simulation of a flood producing rainstorm over Rangamati, Bangladesh using MM5 model
}

\author{
M.N. Ahasan ${ }^{1 *}$, M.A.M. Chowdhury ${ }^{2}$ and D.A. Quadir ${ }^{3}$ \\ ${ }^{1}$ SAARC Meteorological Research Centre (SMRC), Dhaka, Bangladesh \\ ${ }^{2}$ Department of Physics, Jahangirnagar University, Savar, Dhaka, Bangladesh \\ ${ }^{3}$ Department of Physics, Uttara University, Dhaka, Bangladesh
}

\begin{abstract}
Mesoscale simulation of a flood producing rainstorm of 21 June 2004 over Rangamati, Bangladesh has been carried out using the MM5 Model. The model performance was evaluated by examining the different predicted and model derived parameters. The MM5 model suggests that the rainstorm over Rangamati was resulted by the large scale weather circulation associated with active conditions of southwest summer monsoon over the head Bay of Bengal which generated favourable conditions for developing the severe mesoscale convections. The strong confluence of southwesterly low level flow transporting large amount of moisture (which vertically extended up to $350 \mathrm{hPa}$ ) from the Bay of Bengal towards southeast Bangladesh and its neighbourhoods appears to be one of the striking features. An elongated vorticity maximum of the order of $30-40 \times 10^{-5} \mathrm{~s}^{-1}$ was observed across the Rangamati. A well-defined area of low level convergence $\left(-25 \times 10^{-5} \mathrm{~s}^{-1}\right)$ is associated with strong divergence $\left(25 \times 10^{-5} \mathrm{~s}^{-1}\right)$ in the high level $(200 \mathrm{hPa})$ has provided favourable conditions for strong convection. The model simulated realistic pattern of rainfall over Rangamati as compared with TRMM observations. Considering the quantitative comparison of the domain average rainfall with TRMM observations, it is found that the model over predicts by $12 \%$ as compared with TRMM observed rainfall.
\end{abstract}

Keywords: Rainstorm, TRMM; Cumulus Parameterization Scheme; MM5 Model; Convection

*Corresponding author E-mail: nazmul_smrc@yahoo.com 


\section{INTRODUCTION}

Rangamati $\left(22.53^{\circ} \mathrm{N}, 92.20^{\circ} \mathrm{E}\right)$ - the southeastern hilly city of Bangladesh (latitudes $20^{\circ} 34^{\prime}-26^{\circ} 38^{\prime} \mathrm{N}$ and longitudes $88^{\circ} 01^{\prime}-92^{\circ} 41^{\prime} \mathrm{E}$ ) is situated on the western slopes of Mizo hills and Arakan Mountains (Prasad, 2005). Rangamati is very different in terms of topography from the rest of the country, as the city is a part on the hilly regions.

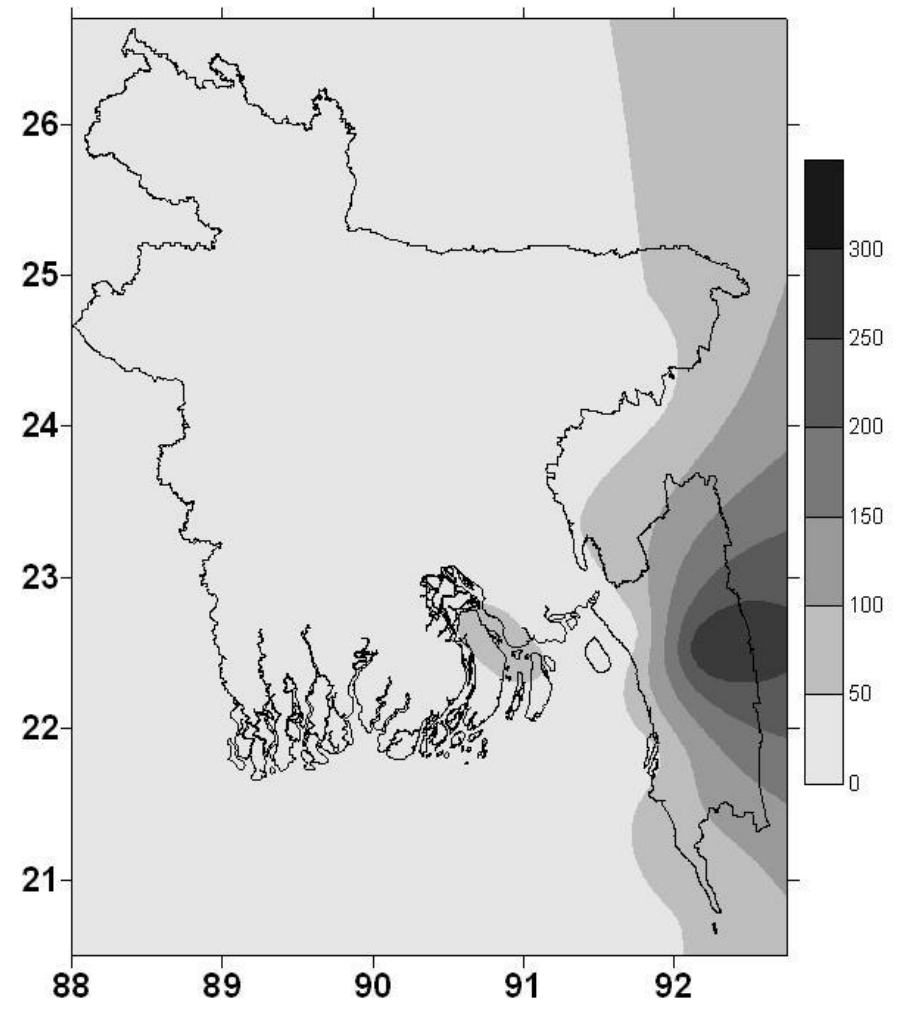

Figure 1: Map showing the location of rain gauge stations of Bangladesh Meteorological Department (BMD) along with the study area Rangamati $\left(22.53^{\circ} \mathrm{N}, 92.20^{\circ} \mathrm{E}\right)$

On 21 June 2004, Rangamati received unprecedented heavy rainfall and most of the part of the city was inundated. This extraordinary rainfall event was localized over Rangamati region and recorded $403 \mathrm{~mm}$ of rainfall within a span of $24 \mathrm{hrs}$. This torrential rain disrupted life in the city by causing severe flash floods. The event resulted in large human and economic losses due to flash flood over the city. The location of rain gauge stations of Bangladesh Meteorological Department (BMD) along with the study area Rangamati $\left(22.53^{\circ} \mathrm{N}, 92.20^{\circ} \mathrm{E}\right)$ is shown in Figure 1.

Rainstorms become significant in human affairs when they are combined with other hydrological elements. The problem of forecasting heavy precipitation is 
especially difficult since it involves creating a quantitative precipitation forecast, recognized as a challenging task ${ }^{1}$. Simulation of active mesoscale systems such as western disturbances, severe thunderstorms, tropical cyclones and heavy rainfall episodes during active monsoon season, with high-resolution mesoscale models such as the Fifth-Generation PSU/NCAR Mesoscale Model (MM5), has been attempted by many researchers ${ }^{2-7}$. Application of NWP model in summer monsoon weather research and forecasting is very little in Bangladesh. However, some works have been done on summer monsoon heavy rainfall over Bangladesh using NWP model ${ }^{9-12}$.

Prasad (2005) has carried out the study on Monsoon forecasting with a limited area numerical weather prediction systems ${ }^{9}$. He identified some heavy rainfall events from the summer monsoon season of 1987, 1997 and 2002 over Bangladesh and northeast India. He investigated the synoptic situations responsible for occurring the heavy rainfall using FSU limited area model and he also forecasted the events. Employment of MM5 in simulating MCSs developed in and around Bangladesh has been studied by Akter and Islam (2009) ${ }^{13}$. They tested the sensitivity of cumulus parameterization schemes (CPS) for the prediction of thunderstorms and found that the Anthes-Kuo CPS is suitable for the prediction of thunderstorms during pre-monsoon season in and around Bangladesh. Ahasan et al., (2014), studied the sensitivity test of different cumulus parameterization schemes in MM5 modeling systems for estimation of monsoon heavy rainfall over Bangladesh ${ }^{12}$. The Anthes-Kuo cumulus parameterization schemes with MRF planetary boundary layer have been found suitable for estimation of monsoon heavy rainfall. Ahasan et al., $(2011,2013)$ also carried out the research work on simulation of a heavy rainfall event on 14 September 2004 over Dhaka, Bangladesh and on 11 June 2007 over Chittagong, Bangladesh respectively using MM5 Model ${ }^{10,11}$. He identified the some synoptic situations responsible for occurring the heavy rainfall over Dhaka and Chittagong, Bangladesh.

The present study has been undertaken to simulate the flood producing rainstorm which occurred over Rangamati, Bangladesh on 21 June 2004 using the MM5 model with triple nested high resolution domain with grid spacing of 45,15 and $5 \mathrm{~km}$ in the horizontal. The study was also aimed to identify the atmospheric conditions, which triggered and maintained such an event. The study is new in the context of Bangladesh and will improve the general understanding of the heavy rainfall processes during summer monsoon.

\section{DATA USED, MODEL EXPERIMENTAL SETUP AND METHODOLOGY}

The Fifth-Generation PSU/NCAR Mesoscale model ${ }^{14,15}$ version 3.7 as adopted for mesoscale weather research and simulation at SAARC Meteorological Research Centre (SMRC), Dhaka, Bangladesh has been used for this study. The data used, experimental setup of the model and methodology of the study are provided in this section. 


\subsection{Data used}

The NCEP Final (FNL) operational model global tropospheric analyses data on $1.0^{\circ} \times 1.0^{\circ}$ grids covering the entire globe every 6 -h were used for model initialization and as lateral boundary conditions. The United States Geological Survey (USGS) topographic data GTOPO30 (Interpolated depending on resolution) were used as earth surface topography and 25 Categories USGS data were used as vegetation / land use. The 5 Layer soil moisture data were used as land surface processes.

The daily $0.25^{\circ} \times 0.25^{\circ}$ resolution TRMM 3B42V6 rainfall data have been downloaded from their website (http://lake.nascom.nasa.gov) to justify the model simulated rainfall structure, development time and location. Moreover, daily observed rainfall data of 34 Meteorological stations of Bangladesh have been collected from the archive of Bangladesh Meteorological Department (BMD) to validate the model simulated rainfall.

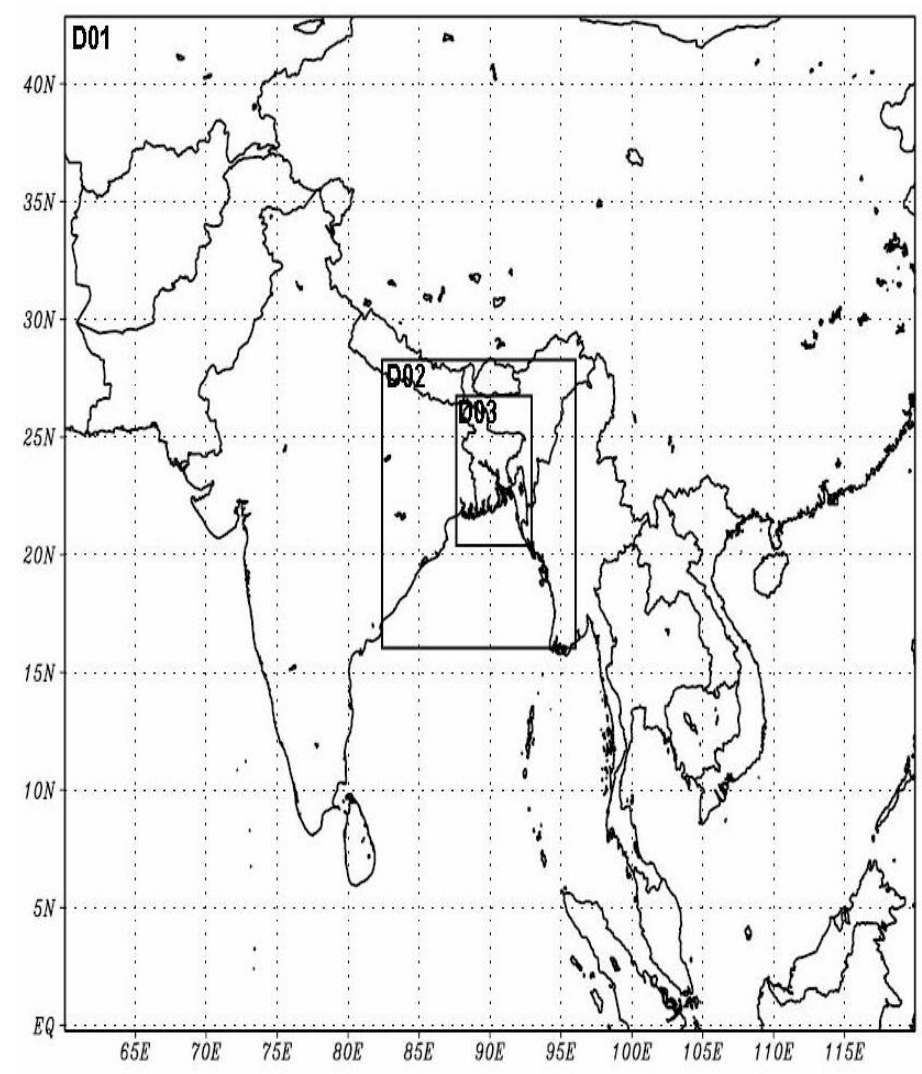

Figure 2: Triple nested domains of MM5 model

\subsection{Model experimental setup and methodology}

The MM5 model is run on triple-nested domains at 45, 15 and $5 \mathrm{~km}$ resolutions using Anthes-Kuo cumulus parameterization scheme ${ }^{16}$ based on 0000 UTC of 20 June 2004 (more than $24 \mathrm{hrs}$ before of the event) initial condition. The configured domains 
are shown in Figure 2. Domain 1 (D1) is the coarsest mesh and has $120 \times 150$ grid points in the north-south and east-west directions respectively with a horizontal grid spacing of $45 \mathrm{~km}$. Within the domain D1, domain 2 (D2) is nested with 100×94 grid points at $15 \mathrm{~km}$ grid spacing. The fine-mesh domain 3 (D3) is $151 \times 115$ points with 5 $\mathrm{km}$ grid spacing. Bangladesh is the main focus area in this study. The model uses two way nesting, where coarse grid data are interpolated to finer grid boundaries and the finer grid provides updated data to the coarse grid. All these 3 domains are centered at $23^{\circ} \mathrm{N}, 90^{\circ} \mathrm{E}$ over Bangladesh to represent the regional-scale circulations and to extract the complex meteorological features in the synoptic and sub-synoptic scales. All these domains were configured to have the same vertical structure of 23 unequally spaced non-dimensional pressure levels in the sigma coordinate. The other physical parameterization schemes used in this study are the MRF scheme for a planetary boundary layer ${ }^{17}$, simple ice for an explicit moisture scheme ${ }^{18}$, simple cooling as radiation scheme and five layer soil model as land surface processes.

The different predicted parameters like mean sea level pressure, $200 \mathrm{hPa}$ level geo-potential height, upper and lower level circulations, vertical wind shear, low level relative vorticity, low level convergence, upper level divergence, horizontal and vertical profile of moisture and rainfall fields were analyzed and discussed. The model simulated rainfall was compared against the rainfall recorded through TRMM observations. The TRMM data is continuous over space and the horizontal resolution is comparable with that of the model output which demonstrates extra advantage of using TRMM data compared to BMD rain gauge observations in the meteorological stations having large spatial gaps from one station to other. The model simulated precipitation at surface level is considered as rainfall throughout the study.

\section{RESULTS AND DISCUSSION}

The results of the present study have been discussed in the following sections.

\section{(a) Mean sea level pressure}

Model simulated mean sea level pressure (hPa) for D1 domain, valid for 00 UTC of 21 June 2004 is presented in Figure 3. The figure shows the east-west running monsoon trough which is positioned close to the foot hills of Himalayas. This is a wellknown situation of 'break monsoon' condition over central India and active monsoon condition over Bangladesh and nearby territory of north, northeast India and Bhutan ${ }^{19}$ which seems to be a prominent feature responsible for this event. One branch of this seasonal monsoon trough runs towards the northeast India through the northeast Bangladesh, which is favourable for heavy rainfall over the southeast region (Rangamati) of the country and neighbourhoods.

The heat low over Pakistan is strong. The pressure at the centre of the heat low is about $996 \mathrm{hPa}$ and that over the southern part of India is about $1011 \mathrm{hPa}$. Monsoon flow is relatively strong due to this north-south pressure gradient. The above synoptic features provided favourable conditions for developing the severe mesoscale convections 
resulting heavy rainfall over the areas of southeast Bangladesh.

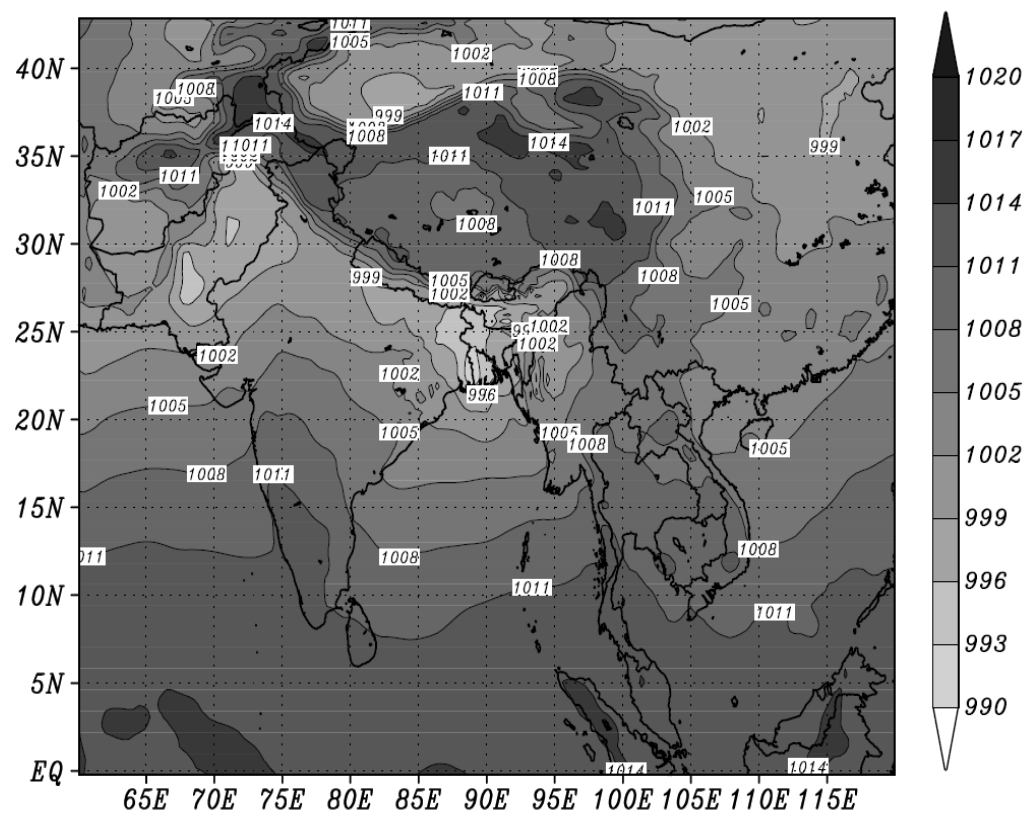

Figure 3: Mean sea level pressure (hPa), valid for 00 UTC of 21 June 2004

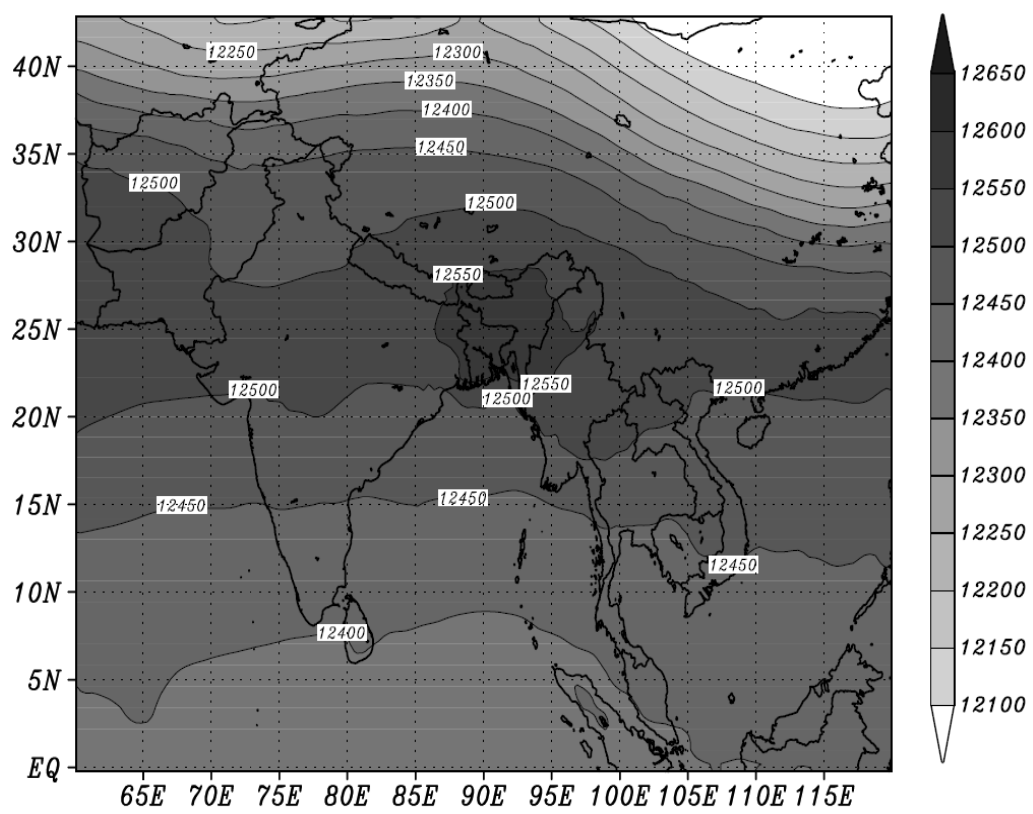

Figure 4: Geo-potential height (m) at $200 \mathrm{hPa}$ level, valid for 00 UTC of 21 June 2004

\section{(b) Geo-potential height field at $200 \mathrm{hPa}$ level}

The geo-potential height field at $200 \mathrm{hPa}$ level for 21 June 2004 at $00 \mathrm{UTC}$ has been shown in Figure 4. The climatological normal position of the high pressure zone at 
$200 \mathrm{hPa}$ represented the Tibetan high is along $32^{\circ} \mathrm{N}$. It is found that the high pressure zone is shifted towards the south than the normal position. The axis of the high pressure zone lies along $25^{\circ} \mathrm{N}$. The model generated structure and position of the $200 \mathrm{hPa}$ geopotential height field deviate to a large extend $\left(\sim 7^{\circ}\right)$ towards south from its climatological normal position $\left(32^{\circ} \mathrm{N}\right)$. The high pressure zone laid over the southeast region of Bangladesh and neighbourhood covering the Rangamati region.
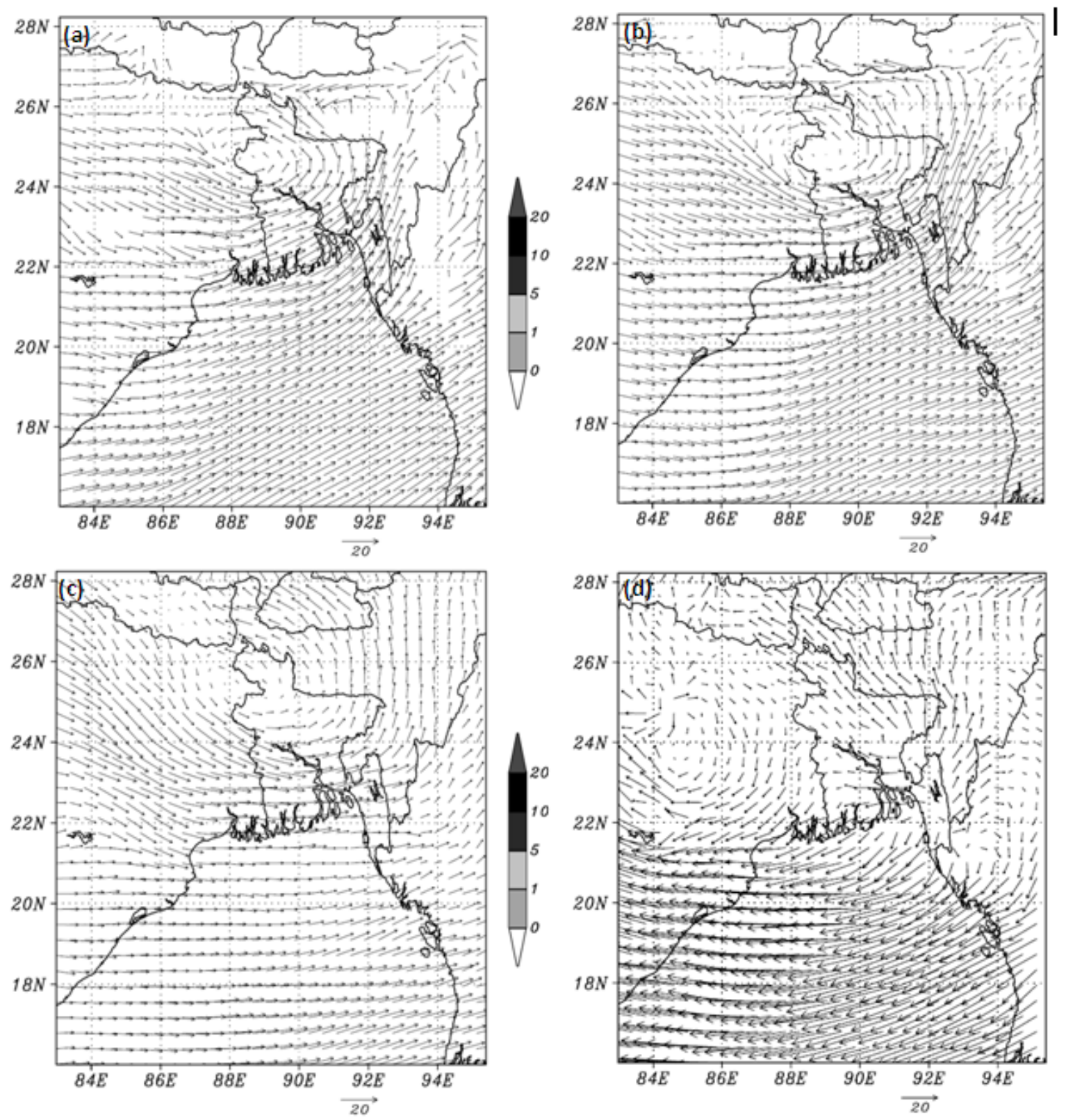

Figure 5: Wind field $\left(\mathrm{ms}^{-1}\right)$ analysis valid for 06 UTC of 21 June 2004 at (a) $925 \mathrm{hPa}$, (b) $850 \mathrm{hPa}$, (c) $500 \mathrm{hPa}$ and (d) $200 \mathrm{hPa}$

\section{(c) Lower and upper level wind field}

The distribution of low level wind at $925 \mathrm{hPa}$ and $850 \mathrm{hPa}$ level, and mid-level and upper level wind at $500 \mathrm{hPa}$ and $200 \mathrm{hPa}$ level valid for $06 \mathrm{UTC}$ of 21 June 2004 
has been presented in Figure 5(a-d). The prominent feature is a strong southwesterly low level flow transporting moisture from the Bay of Bengal into southeast Bangladesh [Figure 5(a-b)]. A jet streak of about $30 \mathrm{~ms}^{-1}$ (58 knots) over southeast Bangladesh and its neighbourhood is a prominent feature marking the strong vertical wind shear in the lower troposphere [Figure 5(a-b)]. A cyclonic circulation is seen in the lower level centering over the northwestern Bangladesh which extends up to the $500 \mathrm{hPa}$ level or more, exhibiting the fact that monsoon circulation is dominant up to the mid troposphere. In the $200 \mathrm{hPa}$ level wind field, it is seen that the traditional large scale anticyclonic flow does not exist. The anticyclonic field is found to be broken with one strong out flow zone over the southeastern Bangladesh and its vicinities, and another anticyclonic weak zone over India.

\section{(d) Vertical wind shear}

Vertical wind shear of the u component of wind $\left(\mathrm{ms}^{-1}\right)$ in the lowest $6 \mathrm{~km}$ of the atmosphere $(500-925 \mathrm{hPa})$, at 06 UTC of 21 June 2004 is presented in Figure 6. It is found that the southeast region of Bangladesh and neighbourhoods was characterized by the strong vertical wind shear. A core of strong wind shear of the order of $15-18 \mathrm{~ms}^{-1}$ may be seen in the southeast part of Bangladesh and neighbourhood is prominent. Vertical wind shear is an important dynamical factor in the development of convective systems in the form of thunderstorms and tornadoes ${ }^{20}$.

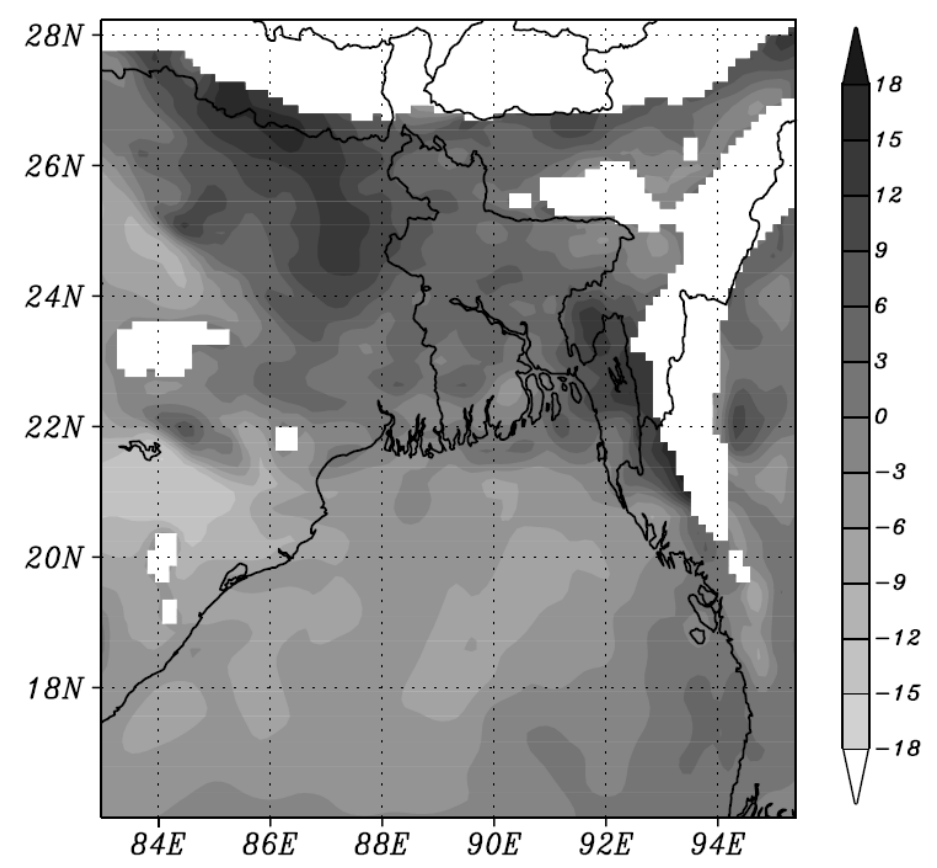

Figure 6: Vertical wind shear of the u component of wind $\left(\mathrm{ms}^{-1}\right)$ in the lowest $6 \mathrm{~km}$ of the atmosphere (500-925 hPa), valid time 06 UTC of 21 June 2004 


\section{(e) Low level relative vorticity}

The low level relative vorticity field at $925 \mathrm{hPa}$ level valid for $06 \mathrm{UTC}$ of 21 June, 2004 is presented in Figure 7. It is found that an elongated vorticity maximum of the order of $30-40 \times 10^{-5} \mathrm{~s}^{-1}$ was observed across the southeast region (Rangamati) of Bangladesh and neighbourhoods. The vorticity field is generated obviously due to the horizontal wind shear in the meridional wind flow.

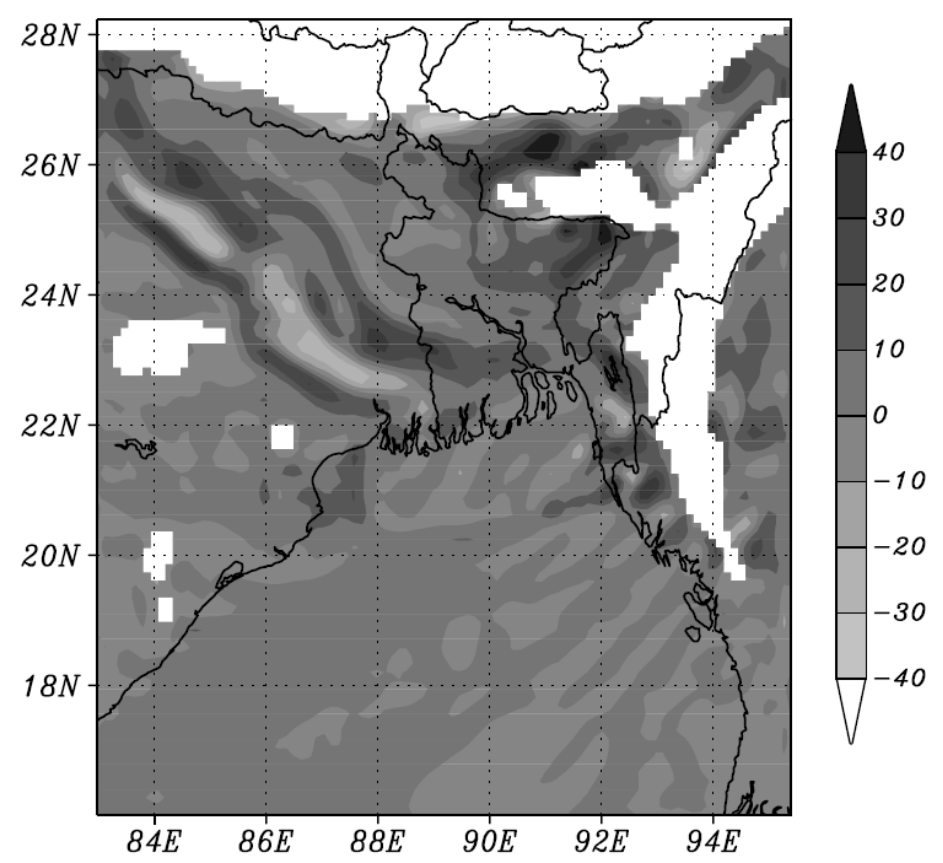

Figure 7: Low level relative vorticity (unit: $\times 10^{-5} s^{-1}$ ) at $925 \mathrm{hPa}$ valid for $06 \mathrm{UTC}$ of 21 June 2004

\section{(f) Low level convergence and upper level divergence}

Low level convergence and upper level divergence are the important parameters to analyze the convection systems. The distribution of convergence and divergence at $925 \mathrm{hPa}$ and $200 \mathrm{hPa}$ are shown in Figure 8(a-b) respectively. The positive value indicates divergence and negative value indicates convergence. A well-defined area of low level convergence of the order of $-25 \times 10^{-5} \mathrm{~s}^{-1}$ over the southeast region (Rangamati region) of the country is clearly seen in the figure [Figure 8(a)]. Sea level pressure (Figure 3) and low level wind patterns [Figure 5 (a)] also indicate the convergence over the southeast Bangladesh (i.e., Rangamati). The intersection of the area of convergence by the southwesterly low level wind is a significant feature favourable for severe convective activity. This strong low level convergence associated with strong outflow (divergence) in the high level (200 hPa) [Figure 5(d) and Figure 8(b)] has provided favourable conditions for strong convection and production of very high rainfall. 

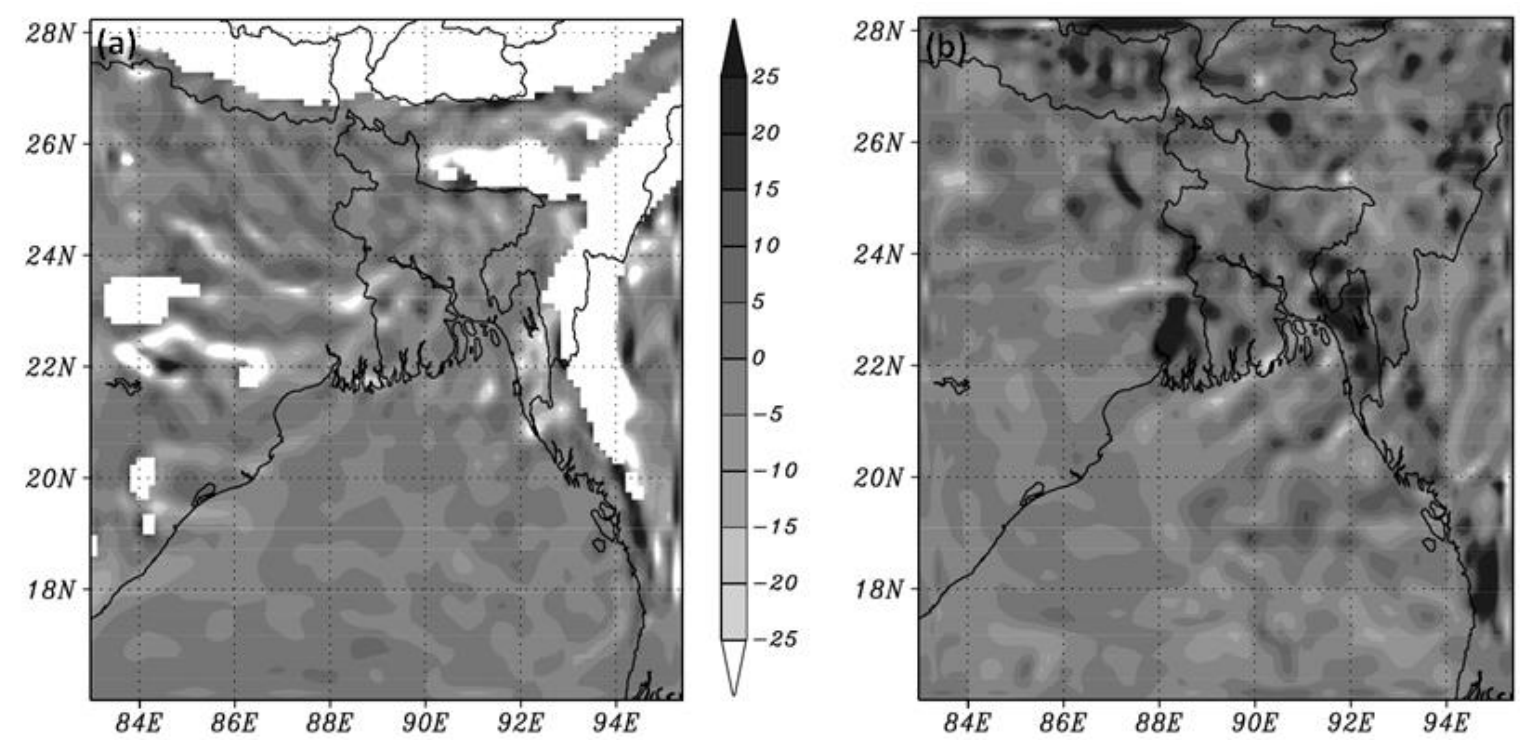

Figure 8: Distribution of divergence field (unit: $\times 10^{-5} \mathrm{~s}^{-1}$ ) valid for 06 UTC of 21 June 2004 at (a) $925 \mathrm{hPa}$ and (b) $200 \mathrm{hPa}$
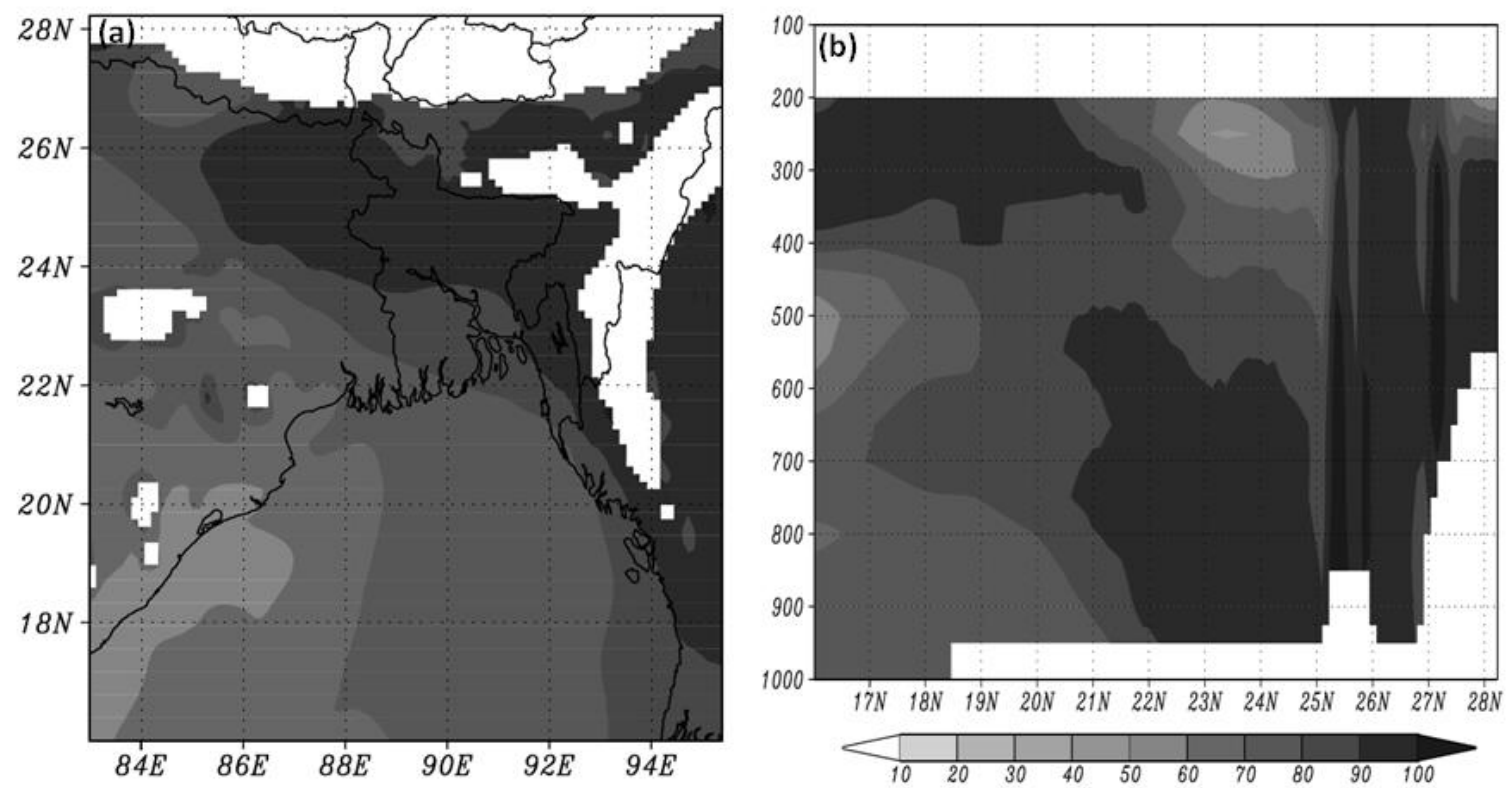

Figure 9: Distribution of relative humidity at (a) $925 \mathrm{hPa}$ and vertical profile of relative humidity along the longitude of Rangamati $\left(92.20^{\circ} \mathrm{N}\right)$, Bangladesh (b) valid for 00UTC of 21 June 2004.

\section{(g) Relative humidity}

Spatial distribution of relative humidity at 00 UTC of 21 June 2004 is presented in Figure 9(a). It is found that the magnitude of humidity is very high over the southeast 
and north of Bangladesh. The circulation of southwesterly low level flow transports plentiful moisture from the Bay of Bengal to the areas of southeast Bangladesh and its neighbourhoods [Figure 5(a)]. It is seen that the high humidity spreads over a large area of the Bay of Bengal which converges along a narrow zone in and around Rangamati. This convergence of moisture field enforces the air to rise up causing convection over this area. The vertical profile of the relative humidity field at 00 UTC of 21 June 2004 along the longitude $92.20^{\circ} \mathrm{E}$ passing across Rangamati is presented in Figure $9(\mathrm{~b})$. It is found that the vertical extent of high humidity reaches up to $350 \mathrm{hPa}$ over Rangamati along a wide vertical column of the troposphere. This clearly indicates the vertical growth of the convective system that produced the rainfall of high intensity.

\section{(h) Rainfall analysis}

The model simulated 24-h accumulated rainfall on 21 June 2004 for domain 3 (D3) at $5 \mathrm{~km}$ resolution which is given in Figure 10(a). The model simulated rainfall has been compared spatially with the TRMM 3B42V6 is shown in Figure 10(b). The TRMM data is continuous over space and the horizontal resolution is comparable with that of the model output which demonstrates extra advantage of using TRMM data compared to BMD rain gauge observations in the meteorological stations having large spatial gaps from one station to other.

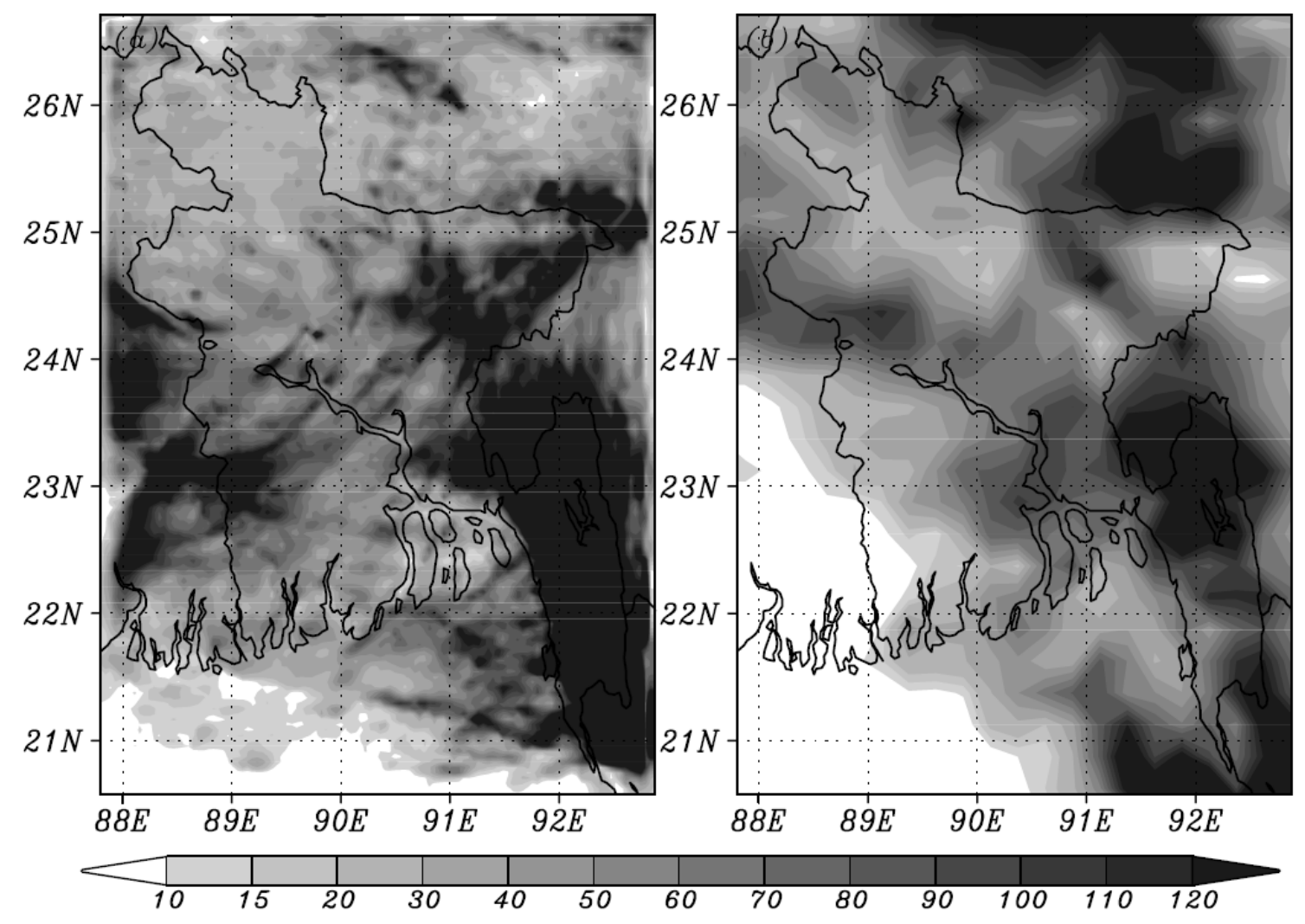

Figure 10: Spatial distribution of 24-h accumulated rainfall (mm) of (a) MM5 model, and (b) TRMM 3B42V6 observed rainfall (mm) on 21 June 2004 
The model simulated rainfall indicates high values over Rangamati and its surrounding areas agreeing well with observations produced by TRMM. The model simulated rainfall over the country overestimated the rainfall compared to that of TRMM. However, the MM5 model not only captured the location of the heavy rainfall area over Rangamati and its neighbourhoods but also in many other places providing a picture of spatial variability. Thus it is expected that the model would have generated higher than realistic rainfall throughout the country. It is to mention in this regards that the network of rain-gauge stations of Bangladesh is not dense enough to capture the realistic picture of localized mesoscale processes unless one or more stations are located on the passage of convective systems [Figure1]. So far the TRMM data is concerned, it was found by Islam and Uyeda (2007) that TRMM underestimates the monsoon rainfall in this region. Thus, the MM5 model-simulated rainfall seems to be more or less realistic both for quantitative assessment of rainfall and geographical distribution.

Considering the quantitative comparison of the domain average rainfall with TRMM and BMD observations, it is found that the model over predicts rainfall by $12 \%$ as compared with TRMM.

\section{CONCLUSIONS}

On the basis of the present study, the following conclusions are drawn:

(1) The MM5 model suggests that the flood producing rainstorm over Rangamati was resulted by the large scale weather circulation associated with active conditions of southwest summer monsoon over the head of the Bay of Bengal which generated favourable conditions for developing the severe mesoscale convections. The pressure at the centre of the heat low was $996 \mathrm{hPa}$ and that over southern part of India was $1011 \mathrm{hPa}$. The intensity of north-south pressure gradient was also strong ( 15 hPa).

(2) The model generated structure and position of the $200 \mathrm{hPa}$ geo-potential height field (known as Tibetan high) deviate to a large extend $\left(\sim 7^{\circ}\right)$ towards south from its climatological normal position $\left(32^{\circ} \mathrm{N}\right)$ and laid just over the heavy rainfall area (Rangamati).

(3) The strong confluence of southwesterly low level flow transporting large amount of moisture from the Bay of Bengal towards southeast Bangladesh and its neighbourhoods appears to be one of the striking features behind the strong convection over southeast Bangladesh. The vertical extent of relative humidity reaches up to upper troposphere along a narrow vertical column situated in the areas of the high rainfall activity.

(4) Advection of strong humidity fields by low level flow streams from extended areas of the Bay of Bengal which confluence in a relatively small area over Rangamati and its neighbourhoods due to the strong convergence of wind field over these areas.

(5) An elongated vorticity maximum of the order of $30-40 \times 10^{-5} \mathrm{~s}^{-1}$ was observed across the southeast region (Rangamati) of Bangladesh and neighbourhoods. 
(6) A well-defined area of low level convergence of the order of $-25 \times 10^{-5} s^{-1}$ is clearly seen over the southeast region (Rangamati region) of the country. This strong low level convergence associated with strong outflow (divergence) in the high level $(200 \mathrm{hPa})$ has provided favourable conditions for strong convection and production of very high rainfall.

(7) The model simulation produces realistic pattern of rainfall over Rangamati and its neighbourhoods as compared with TRMM observations. Model simulated the details structure of the spatial patterns of rainfall over Bangladesh. Considering the quantitative comparison of the domain average rainfall with TRMM observations, it is found that the model over predicts rainfall by $12 \%$ as compared with TRMM observed rainfall.

Finally, it may be concluded that the Fifth-Generation PSU/NCAR Mesoscale Model MM5 version 3.7 with the right combination of the nesting domain, horizontal resolution and cumulus parameterization schemes was able to simulate the rainstorm over Rangamati and associated favourable synoptic features reasonably well, though there are some spatial and temporal biases in the simulated rainfall pattern.

\section{ACKNOWLEDGEMENT:}

The authors are thankful to Dr. Md. Nazrul Islam, Professor, Department of Meteorology, King Abdul Aziz University, Jeddah, K. S. A for helpful suggestions and encouragement. Thanks are due to Director, SMRC for providing necessary permission and facility to carry out this research work.

\section{REFERENCES}

1. A.D. Charles, Scientific approaches for very short-range forecasting of severe convective storms in the United States of America, International Workshop on Observation/Forecasting of Meso-scale Weather and Technology of Reduction of Relevant Disasters, Tokyo, Japan, (1993), 181-188.

2. S.A. Braun and W.K. Tao, Sensitivity of high-resolution simulations of hurricane Bob (1991) to planetary boundary layer parameterizations, Monthly Weather Review, 128 (2000), 3941-3961.

3. P.K. Patra, M.S. Santhanam, K.V.J. Potty, M.T. Tewari and P.L.S. Rao, Simulation of tropical cyclones using regional weather prediction models, Current Science, $\underline{79}$, (2000) 70-78.

4. N.L. Seaman, Meteorological modeling for air-quality assessments, Atmospheric Environment, 34, (2000) 2231-2259.

5. S. Das, Mesoscale and cloud resolving scale simulation of a heavy precipitation episode and associated cloud system using MM5 model, INDO-US Workshop on Weather and Climate Modeling, New Delhi, (2002).

6. R.K. Jenamani, S.C. Bhan, and S.R. Kalsi, Observationalfforecasting aspects of the meteorological event that caused a record highest rainfall in Mumbai, Current Science, 90, (2006) 1344-1362.

7. A.K. Bohra, Swati Basu, E.N. Rajagopal, G.R. Iyengar, M. Das Gupta, R. Ashrit and B. Athiyaman, Heavy rainfall episode over Mumbai on 26 July 2005: Assessment of NWP 
guidance, Current Science, 90(9), (2006) 1188-1194.

8. A.J. Litta, B. Chakrapani, and K. Mohnakumer, Mesoscale simulation of an extreme rainfall event over Mumbai, India, using a high-resolution MM5 model, Meteorol. Appl. 14, (2007) 291-295.

9. K. Prasad, Monsoon Forecasting with a Limited Area Numerical Weather Prediction System, SAARC Meteorological Research Centre (SMRC), SMRC Scientific Report No.11 (2005).

10. M.N. Ahasan, M.A.M. Chowdhury and D.A. Quadir, Simulation of a Heavy Rainfall Event on 14 September 2004 over Dhaka, Bangladesh Using MM5 Model, J. Sci. Res. 3(2), (2011) 261-270.

11. M.N. Ahasan, M.A.M. Chowdhury and D.A. Quadir, Simulation of a heavy rainfall event of 11 June 2007 over Chittagong, Bangladesh using MM5 model, MAUSAM, 64(3), (2013) 405-416.

12. M.N. Ahasan, M.A.M. Chowdhury and D.A. Quadir, Sensitivity test of parameterization schemes of MM5 model for prediction of the high impact rainfall events over Bangladesh. Journal of Mechanical Engineering (JME), The Institution of Engineers, Bangladesh (IEB), 44(1), (2014) 33-42

13. N. Akter and M.N. Islam, Employment of MM5 in simulating MCSs developed in and around Bangladesh. MAUSAM 60(2), (2009) 137-146

14. J. Dudhia, D. Gill, K. Manning, W. Wang and C. Bruyere, PSU/NCAR Mesoscale Modeling System (MM5 version 3) tutorial class notes and user's guide, National Center for Atmospheric Research, Boulder, Colorado, USA, (2002).

15. G.A. Grell, J. Dudhia, and D.R. Stauffer, A description of the 5th generation Penn State/NCAR Mesoscale model (MM5), NCAR technical note, NCAR/TN-398+STR, 117, (1994) 122.

16. R.A. Anthes, A cumulus parameterization scheme utilizing a one dimensional cloud model, Monthly Weather Review, 105, (1977) 270-286.

17. S.Y. Hong, and H.L. Pan, Nonlocal boundary layer vertical diffusion in a medium-range forecast model, Monthly Weather Review, 124, (1996) 2322-2339.

18. J. Dudhia, Numerical study of convection observed during the winter monsoon experiment using a mesoscale two-dimensional model, Journal of Atmospheric Sciences, 46, (1989) 3077-3107.

19. D.A. Quadir, M.A. Hussain and M.N. Ahasan, Climatic characteristics of temperature and precipitation of Bhutan, MAUSAM, 58, (2007) 9-16.

20. J.R. Holton, An Introduction to Dynamic Meteorology, Fourth Edition, International Geophysics Series, $\underline{88}$, (2004) 296-313.

21. M.N. Islam, and Hiroshi Uyeda, Use of TRMM in determining the climatic characteristics of rainfall over Bangladesh, Remote Sensing of Environment, 108, (2007) 264-276. 